\title{
OPERASI JOIN KOTERI-k DIPERLUAS
}

\author{
La Ode Muhlis, ${ }^{1}$ Armin Lawi ${ }^{2}$, Amir Kamal Amir ${ }^{3}$
}

\begin{abstract}
Abstrak
Sebagaiman diketahui bahwa koteri- $k$ merupakan perluasan dari definisi koteri yang dapat diterapkan masalah mutex- $k$. Pada mutex- $k$ terdapat sebanyak $k$ proses yang dapat mengakses sumber daya. Selain itu, kita juga mengenal koteri- $k$ khusus yang disebut dengan koteri- $k$ mayoritas dimana untuk setiap korumnya memiliki ukuran yang sama yang ditentukan dengan $|\boldsymbol{Q}|=\left\lceil\frac{n+1}{k+1}\right\rceil$. Terdapat beberapa cara dalam penggabungan koter- $k$ i salah satu diantaranya dan sudah tidak asing lagi yaitu operasi join yang merupakan suatu operasi yang digunakan dalam menggabungkan koteri- $k$ mayoritas yang diperkenalkan oleh Neilsen dan Mizuno. Pada operasi join, terdapat salah satu sifat yang menyatakan bahwa jika $\boldsymbol{C}_{\boldsymbol{1}}$ dan $\boldsymbol{C}_{\mathbf{2}}$ tak-terdominasi maka $\boldsymbol{C}_{\boldsymbol{3}}$ tak-terdominasi. Ternyata sifat tersebut tidak selamanya berlaku sehingga mengakibatkan koteri- $k$ yang dihasilkan dari operasi join menjadi terdominasi.

Tujuan dari penelitian ini yaitu memperkenalkan suatu cara baru dalam menggabungkan koteri- $k$ mayoritas tak-terdominasi yang disebut dengan operasi join diperluas. Dimana operasi join diperluas ini adalah suatu operasi yang dikembangkan dari operasi join yang dibangun dengan cara menggabungkan dua koteri- $k$ mayoritas $\boldsymbol{C}_{\boldsymbol{1}}$ dan $\boldsymbol{C}_{\mathbf{2}}$ yang memiliki ukuran korum yang sama masingmasing atas semesta tak-kosong $\boldsymbol{U}_{\mathbf{1}}$ dan $\boldsymbol{U}_{\mathbf{2}}$ dengan unsur tereliminasi $\boldsymbol{x} \in \boldsymbol{U}_{\mathbf{1}}$, dimana $\boldsymbol{U}_{\mathbf{1}} \cap \boldsymbol{U}_{\mathbf{2}}=\varnothing$ untuk membentuk $\boldsymbol{C}_{\mathbf{3}}$ atas semesta tak-kosong $\boldsymbol{U}_{3}=\left\{\left(\boldsymbol{U}_{\mathbf{1}}-\{\boldsymbol{x}\} \cup \boldsymbol{U}_{2}\right)\right\}$. Hasil dari penelitian ini menunjukan bahwa untuk penggabungan dua koteri- $k$ mayoritas tak-terdominasi dengan mengguankan operasi join diperluas akan selalu menghasilkan koteri- $k$ tak-terdominasi dengan nilai $k$ sebelum dan setelah dilakukan operasi penggabungan tidak mengalami perubahan.
\end{abstract}

Kata kunci: Koteri- $k$, koteri- $k$ mayoritas, koteri- $k$ tak terdominasi, operasi join dan operasi join diperluas.

\begin{abstract}
Operation of merging of $k$-coteries is not new. Where one of incorporation operations of the $k$-coteri has been introduced by Neilsen and Mizuno. However, for research that combined the two forms of k-majority coterie with the same $k$ has not been done by previous researchers. In this study, the background of how to combine the two forms of koteri majority to obtain a new majority $k$ kerier $k$ before and after the operation is fixed and unchanged.

$k$-Coterie is an extension of the definition of coterie that can be applied to the k-mutex problems. In $k$-coterie there are as many processes that can access resources. And also we know that in $k$-coterie there are $k$-majority coterie. $k$-Majority coterie is a unik $k$-coterie in which for each measure of the $k$-majority coterie has the same quorum size which can be determined by $|Q|=\left[\frac{n+1}{k+1}\right]$. There are several ways to combine the k-majority coteries, one of them and familiar is a join operation which is an operation combining two $k$ - majority coteries. Where, this join operation was first introduced by Neilsen and Mizuno. The purpose of this research is to introduce a new way to combine k-majority coterie called ${ }^{l}$ extended join operation. Which is this extended join operation is built by combining the
\end{abstract}

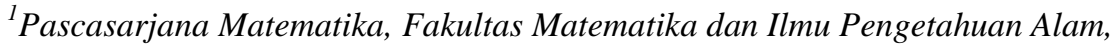

Universitas Hasanuddin

${ }^{2,3}$ Departemen Matematika, Fakultas Matematika dan Ilmu Pengetahuan Alam,

Universitas Hasanuddin 
two k-majority coteries $C_{1}$ and $C_{2}$ respectively under the non-empty set $U_{1}$ and $U_{2}$ with the eliminated element $x \in U_{1}$, where $U_{1} \cap U_{2}=\emptyset$ to form $C_{3}$ under the non-empty set $U_{3}=\left\{\left(U_{1}-\{x\} \cup U_{2}\right)\right\}$. The results of this study show that for the merging of two $k$-majority coteriie by using expanded join operation will still be obtained $k$ - majority coterie under the non-empty set $U_{3}=\left\{\left(U_{1}-\{x\} \cup U_{2}\right)\right\}$ with the value of $k$ before and after done operations of merging remain unchanged.

Keywords: $k$-Coterie, $k$-majority coterie,non-dominated $k$-coterie, join operation and extended join operations.

\section{PENDAHULUAN}

Sistem terdistribusi (distributed system) merupakan sekumpulan elemen atau proses yang saling terhubung satu sama lain yang membentuk suatu kesatuan untuk menyelesaikan suatu tujuan yang spesifik atau menjalankan seperangkat fungsi dimana setiap elemen atau proses tersebut saling berkomunikasi dengan cara saling bertukar pesan (massage passing). Salah satu keunggulan dari sistem terdistribusi adalah dimana kemungkinan adanya kegagalan proses yang tidak diketahui namun kegagalan proses tersebut tidak dapat membuat kegagalan pada sistem secara keseluruhan. Sementara kekurangan dari sistem terdistribusi yaitu bahwa terjadinya masalah tabrakan data, adanya konflik akses, masalah pemilihan kepemimpinan dan lain-lain. Untuk mengatasi permasalah ini, maka diperlukan suatu algoritma sinkronisasi permasalahan yang dikenal dengan algoritma mutual exlusion problem (algoritma masalah mutex). Permasalahan mutex ini, pertama kali di uraikan dan diselesaikan oleh Dijkstra (Lamport, 1986). Namun, permasalahan mutex juga dapat dipandang sebagai permasalahan yang sangat mendasar dan krusial dalam hal merancang sistem terdistribusi (Jiang \& Huang, 1994; Kakugawa et al., 1994; Lawi et al., 2005). Tedapat beberapa algoritma yang telah mengimplementasikan masalah mutex tersebut kedalam lingkup sistem terdistribusi yaitu dalam hal ini adalah sistem terdistribusi dengan cara saling bertukar pesan (massage passing) yaitu seperti yang dilakukan oleh (Lawi et al., 2006; Neilsen \& Mizuno, 1994; Neilsen, 1997).

Pada algoritma masalah mutex terbagi menjadi dua bentuk algoritma. Yang pertama algoritma barbasis tanda (token-based) yaitu suatu proses yang mengakses sumberdaya ketika memiliki token. Dan yang kedua adalah algoritma berbasis izin (permission based) yaitu suatu proses yang mengakses sumberdaya jika proses tersebut berhasil mengumpulkan izin dari berbagai proses dalam sistem tersebut. Untuk algoritma berbasis izin juga terbagi menjadi dua bagian yaitu algoritma berbasis izin klasik dan algoritma berbasis himpunan korum. Jika dibandingkan dengan algoritma berbasis izin klasik, algoritma berbasis himpunan korum memiliki keunggulan yang lebih baik dari pada algoritma berbasis izin klasik. 


\section{La Ode Muhlis, Armin Lawi, Amir Kamal Amir}

Keunggulan dari algoritma himpunan berbasis korum ini yaitu memiliki reliabilitas yang cukup baik dan juga memberikan jumlah pertukaran pesan yang jauh lebih sedikit sehingga lebih efisien.

Sehingga masalah mutex dapat dibentuk kedalam sistem himpunan korum yang dikatakan dengan koteri sebagai mana yang dikaji oleh Neilsen \& Mizuno (1992), dan Lamport (1986), yang memberikan hasil kajian yaitu nilai cost algoritma yang rendah terhadap penggunaan koteri. Yang dimasud dengan koteri adalah kumpulan atau himpunan dari beberapa korum yang saling beririsan satu sama lain dan untuk setiap korumnya bukan merupakan subset dari atau sama dengan korum lainnya (Neilsen \& Mizuno, 1994). Untuk beberapa penelitian seperti yang dilakukan oleh Agrawal \& El-Abadi (1991); Garcia \& Barbara (1985), memperkenalkan bagaimana membentuk suatu himpunan korum yang disebut dengan koteri.

Selain koteri, kita juga mengenal apa yang disebut dengan koteri- $k$. Koteri- $k$ merupakan pengembangan dari koteri. Secara sederhana, koteri- $k$ dapat didefinisikan sebagai himpunan korum yang memiliki paling banyak $k$ korum yang saling pisah. Dimana, sistem himpunan korum yang mengkaji tentang koteri- $k$ dapat diimplementasikan kedalam masalah alokasi sumberdaya yang di kenal dengan masalah mutex- $k$. Masalah Mutex- $k$ merupakan pengembangan dari masalah mutex yang dinyatakan dengan "terdapat paling banyak $k$ proses yang dapat mengakses sumberdaya". Penerapan masalah mutex- $k$ yang menerapkan algoritma koteri- $k$ juga telah dilakukan oleh Manabe \& Tajima (2004); Kakugawa et al (1994), dimana hasil dari penelitian mereka memberikan nilai cost yang rendah. Sementara Najafi (2008), bagaimana merancang teory graf yang diterapkan kemasalah sistem terdisttribusi dengan nilai cost yang rendah.

Terdapat beberapa cara dalam menggabungkan suatu himpunan korum. Neilsen \& Mizuno (1992), membangun operasi penggabungan koteri maupun koteri- $k$ yang disebut dengan operasi join. Namun operasi join tersebut menghasilkan koteri maupun koteri- $k$ yang terdominasi. Ishak $d k k$ (2016), melakukan pembanguna operasi penggabungan dua koteri mayoritas yang disebut dengan operasi join diperluas sementara untuk koteri- $k$ mayoritas belum dilakukan. Tujuan penelitan ini yaitu membangun definisi penggabungan koteri- $k$ mayoritas untuk mendapatkan suatu koteri- $k$ yang baru dengan nilai $k$ sebelum dan setelah dilakukan operasi masih tetap sama dalam hal ini nilai $k$ tidak mengalami perubahan. 


\section{La Ode Muhlis, Armin Lawi, Amir Kamal Amir}

\section{METODE}

\section{Rancangan Penelitian}

Untuk rancangan penelitian yang akan dilakukan dengan uraian sebagai berikut. Pertama-tama yang akan dikaji adalah tentang sistem terdistribusi. Selanjutnya mengkaji tentang masalah mutex- $k$ dan diteruskan dengan mengkaji materi himpunan korum yang mencakup tentang definisi koteri- $k$, koteri- $k$ mayoritas, dan koteri- $k$ terdominasi. Kemudian melakukan operasi penggabungan koteri- $k$ dengan menggunakan operasi join diperluas untuk mendapatkan suatu koteri- $k$ yang baru. Untuk operasi penggabungan koteri- $k$ ini, yaitu menggabungkan dua bentuk koteri- $k$ mayoritas dengan ukuran korum dan nilai $k$ yang sama untuk mendapatkan koteri- $k$ yang baru dengan ukuran dan banyak korum yang diperoleh melebihi dua koteri- $k$ mayoritas awal sebelum dilakukan operasi. Dan sebagai langkah terakhir yaitu mendefinisikan sifat-sifat opersi join diperluas pada penggabungan koteri- $k$ mayoritas tersebut.

\section{HASIL PENELITIAN}

Penggabugan dua koteri- $k$ mayoritas didefinisikan dengan operasi join diperluas sebagai berikut.

Definisi 1.3. Misalkan $C_{1}=\left\{G_{1}, G_{2}, \ldots, G_{l}\right\}$ dan $C_{2}=\left\{H_{1}, H_{2}, \ldots, H_{l}\right\}$ adalah koteri- $k$ mayoritas masing-masing atas semesta $U_{1}$ dan $U_{2}$, dimana $U_{1} \cap U_{2}=\emptyset$. Operasi join diperluas $C_{1}$ dan $C_{2}$ dengan unsur tereliminasi $x \in U_{1}$ yang membentuk $C_{3}=C_{1} \circledast_{x} C_{2}$ atas semesta $U_{3}=\left\{\left(U_{1}-\{x\}\right) \cup U_{2}\right\}$ didefinisikan sebagai berikut:

$$
C_{3}=C_{1} \circledast_{x} C_{2}=\left\{Q \mid Q=\left\{\begin{array}{ll}
\left(G_{i}-\{x\}\right) \cup H_{p}, & \text { jika } x \in G_{i} \\
\left(\left(G_{i}-\{x\}\right) \cap\left(G_{j}-\{x\}\right)\right) \cup\left(H_{p} \cup H_{q}\right), & \text { jika } x \in G_{i} \cap G_{j} \\
G_{i}, & \text { jika } x \notin G_{i}
\end{array}\right\}\right.
$$

Dimana $G_{i}, G_{j} \in C_{1} ; H_{p}, H_{q} \in C_{1}$; untuk $i \neq j ; p \neq q$.

\section{PEMBAHASAN}

Untuk koteri- $k$ didefinisikan dengan

Definisi 1.1. Koleksi himpunan tak-kosong $C \subseteq 2^{U}$ dikatakan $k$-koteri atas himpunan tak kosong $U$ jika dan hanya jika berlaku syarat

1. Saling pisah: Untuk setiap $r(<k)$ korum yang saling pisah $Q_{1}, \ldots, Q_{r} \in C$ dimana $Q_{i} \cap Q_{j}=\emptyset,(1 \leq i \neq j \leq r)$, terdapat korum $Q \in C$ sedemikian sehingga $Q \cap Q_{i}=\emptyset$, $(1 \leq i \leq r)$.

2. Saling irisan: Untuk setiap $l(>k)$ korum $Q_{1}, \ldots, Q_{l} \in C$, terdapat pasangan korum $Q_{i}, Q_{j}$ sedemikian sehingga $Q_{i} \cap Q_{j} \neq \emptyset,(1 \leq i \neq j \leq l)$. 


\section{La Ode Muhlis, Armin Lawi, Amir Kamal Amir}

3. Minimalitas: $\forall Q_{i}, Q_{j} \in C$ berlaku $Q_{i} \nsubseteq Q_{j}$.

Koteri- $k$ mayoritas adalah himpunan korum yang memiliki ukuran yang sama. Untuk ukuran korum koteri- $k$ mayoritas didefinisikan dengan

Definisi 1.2. Koleksi himpunan $M$ dikatakan k-koteri mayoritas atas himpunan tak-kosong $U$ jika dan hanya jika $M=\{Q(\subseteq U):|Q|=N\}$. Dimana $N=\left[\frac{n+1}{k+1}\right\rceil$, dimana $n=|U|$.

Definisi 1.3 C koteri-k terdominasi atas semesta tak-kosong $U$ jika dan hanya jika terdapat $Q^{\prime}(\subseteq U)$ dimana $Q^{\prime} \notin C_{3}$ yang memenuhi:

1. $\forall Q \in C$ sedemikian sehingga $Q^{\prime} \nsubseteq Q$.

2. Untuk setiap $k$ korum saling pisah $Q_{1}, \ldots, Q_{k} \in C$, terdapat korum $Q_{i}$ sedemikian sehingga $Q^{\prime} \cap Q_{i} \neq \emptyset,(1 \leq i \leq k)$.

3. Terdapat paling banyak $k-1$ korum saling pisah $Q_{1}, \ldots, Q_{k-1} \in C$ dimana $Q_{i} \cap Q_{j}=\emptyset$, $(1 \leq i \neq j \leq k-1)$, sedemikian sehingga $Q^{\prime} \cap Q_{i}=\emptyset,(1 \leq i \leq k-1)$.

Definisi 1.4. Misalkan $C_{1}$ dan $C_{2}$ adalah koteri masing-masing atas semesta $U_{1}$ dan $U_{2}$, dimana $U_{1} \cap U_{2}=\varnothing$. Operasi join $C_{1}$ dan $C_{2}$ dengan satu unsur tereliminasi $x \in U_{1}$ didefinisikan dengan

$$
C_{3}=C_{1} \otimes_{x} C_{2}=\left\{Q \mid Q=\left\{\begin{array}{ll}
\left(G_{i}-\{x\}\right) \cup H_{m}, & \text { jika } x \in G_{i} \\
G_{i}, & \text { jika } x \notin G_{i}
\end{array}, G_{i} \in C_{1}, H_{m} \in C_{2}\right\}\right.
$$

Definisi 1.5. Misalkan $C_{1}=\left\{G_{1}, G_{2}, \ldots, G_{l}\right\}$ dan $C_{2}=\left\{H_{1}, H_{2}, \ldots, H_{l}\right\}$ adalah koteri- $k$ mayoritas masing-masing atas semesta $U_{1}$ dan $U_{2}$, dimana $U_{1} \cap U_{2}=\emptyset$. Operasi join diperluas $C_{1}$ dan $C_{2}$ dengan unsur tereliminasi $x \in U_{1}$ yang membentuk $C_{3}=C_{1} \circledast_{x} C_{2}$ atas semesta $U_{3}=\left\{\left(U_{1}-\{x\}\right) \cup U_{2}\right\}$ didefinisikan dengan:

$$
C_{3}=C_{1} \circledast_{x} C_{2}=\left\{Q \mid Q=\left\{\begin{array}{ll}
\left(G_{i}-\{x\}\right) \cup H_{p}, & \text { jika } x \in G_{i} \\
\left(\left(G_{i}-\{x\}\right) \cap\left(G_{j}-\{x\}\right)\right) \cup\left(H_{p} \cup H_{q}\right), & \text { jika } x \in G_{i} \cap G_{j} \\
G_{i}, & \text { jika } x \notin G_{i}
\end{array}\right\}\right.
$$

Dimana $G_{i}, G_{j} \in C_{1} ; H_{p}, H_{q} \in C_{1}$; untuk $i \neq j ; p \neq q$.

\section{Contoh 1.}

Misalkan diberikan koleksi himpunan $C_{1}$ dan $C_{1}$ masing-masing atas semseta $U_{1}=\{1,2,3,4\}$ dan $U_{2}=\{a, b, c, d\}$ sebagai berikut

$$
\begin{aligned}
& C_{1}=\{\{1,2\},\{1,3\},\{1,4\},\{2,3\},\{2,4\},\{3,4\}\} \\
& C_{2}=\{\{a, b\},\{a, c\},\{a, d\},\{b, c\},\{b, d\},\{c, d\}\}
\end{aligned}
$$

Jika unsur tereliminasi $x=4$, dengan menggunakan operasi join diperoleh $C_{3}$ atas semesta $U_{3}=\{1,2,3, a, b, c, d\}$ yaitu

$$
C_{3}=C_{1} \otimes_{4} C_{2}=\left\{Q \mid Q=\left\{\begin{array}{ll}
\left(G_{i}-\{4\}\right) \cup H_{m}, & \text { jika } 4 \in G_{i} \\
G_{i}, & \text { jika } 4 \notin G_{i}
\end{array}, G_{i} \in C_{1}, H_{m} \in C_{2}\right\}\right.
$$




\section{La Ode Muhlis, Armin Lawi, Amir Kamal Amir}

$$
\begin{aligned}
C_{3}=C_{1} \otimes_{4} C_{2}= & \{\{1, a, b\},\{1, a, c\},\{1, a, d\},\{1, b, c\},\{1, b, d\},\{1, c, d\},\{2, a, b\},\{2, a, c\}, \\
& \{2, a, d\},\{2, b, c\},\{2, b, d\},\{2, c, d\},\{3, a, b\},\{3, a, c\},\{3, a, d\},\{3, b, c\}, \\
& \{3, b, d\},\{3, c, d\},\{1,2\},\{1,3\},\{2,3\}\}
\end{aligned}
$$

Nampak bahwa operasi join menghasilkan koteri- $k$ yang terdominasi sebab dapat ditemukan $Q^{\prime}=\{a, b, c\} \subseteq U(=\{1,2,3, a, b, c, d\})$, dimana $Q^{\prime} \notin C_{3}$ yang memenuhi definisi 1.3 .

\section{Contoh 2.}

Misalkan diberikan koleksi himpunan $C_{1}$ dan $C_{1}$ masing-masing atas semseta $U_{1}=\{1,2,3,4\}$ dan $U_{2}=\{a, b, c, d\}$ sebagai berikut

$$
\begin{aligned}
& C_{1}=\{\{1,2\},\{1,3\},\{1,4\},\{2,3\},\{2,4\},\{3,4\}\} \\
& C_{2}=\{\{a, b\},\{a, c\},\{a, d\},\{b, c\},\{b, d\},\{c, d\}\}
\end{aligned}
$$

Jika unsur tereliminasi $x=4$, dengan menggunakan operasi join diperluas maka

$$
C_{3}=C_{1} \circledast_{4} C_{2}=\left\{Q \mid Q=\left\{\begin{array}{ll}
\left(G_{i}-\{4\}\right) \cup H_{p}, & \text { jika } 4 \in G_{i} \\
\left(\left(G_{i}-\{4\}\right) \cap\left(G_{j}-\{4\}\right)\right) \cup\left(H_{p} \cup H_{q}\right), & \text { jika } 4 \in G_{i} \cap G_{j} \\
G_{i}, & \text { jika } 4 \notin G_{i}
\end{array}\right\}\right.
$$

a. $\left(\left[\left(G_{i}-\{4\}\right)\right]_{i=1}^{i=3}\right) \cup\left(\left[H_{p}\right]_{p=1}^{p=6}\right)=$

$\{\{1, a, b\},\{1, a, c\},\{1, a, d\},\{1, b, c\},\{1, b, d\},\{1, c, d\},\{2, a, b\},\{2, a, c\},\{2, a, d\},\{2, b, c\}$,

$\{2, b, d\},\{2, c, d\},\{3, a, b\},\{3, a, c\},\{3, a, d\},\{3, b, c\},\{3, b, d\},\{3, c, d\}\}$

b. $\left(\left[\left(G_{i}-\{4\}\right) \cap\left(G_{j}-\{4\}\right)\right]_{i, j=1}^{i, j=3}\right) \cup\left(\left[\left(H_{p} \cup H_{q}\right)\right]_{p, q=1}^{p, q=6}\right)=$

$$
\{\{a, b, c\},\{a, b, d\},\{a, c, d\},\{b, c, d\}\}
$$

c. $\left[G_{i}\right]_{i=1}^{i=3}=\{\{1,2\},\{1,3\},\{2,3\}\}$

Dengan demikian diperoleh $C_{3}$ atas semesta $U_{3}=\{1,2,3, a, b, c, d\}$ yaitu

$$
\begin{aligned}
C_{3}=C_{1} \circledast_{4} C_{2}= & \{\{1, a, b\},\{1, a, c\},\{1, a, d\},\{1, b, c\},\{1, b, d\},\{1, c, d\},\{2, a, b\},\{2, a, c\}, \\
& \{2, a, d\},\{2, b, c\},\{2, b, d\},\{2, c, d\},\{3, a, b\},\{3, a, c\},\{3, a, d\},\{3, b, c\}, \\
& \{3, b, d\},\{3, c, d\},\{a, b, c\},\{a, b, d\},\{a, c, d\},\{b, c, d\},\{1,2\},\{1,3\},\{2,3\}\}
\end{aligned}
$$

Nampak bahwa pada operasi join diperluas menghasilkan koteri- $k$ tak-terdominasi sebab tidak dapat ditemukan $Q^{\prime} \subseteq U(=\{1,2,3, a, b, c, d\})$, dimana $Q^{\prime} \notin C_{3}$ yang memenuhi definisi 1.3.

\section{KESIMPULAN DAN SARAN}

Operasi penggabungan dua koteri- $k$ mayoritas yang memiliki ukuran korum dan nilai $k$ yang sama didefinisikan dengan operasi join diperluas yaitu 
$C_{3}=C_{1} \circledast_{x} C_{2}=\left\{Q \mid Q=\left\{\begin{array}{ll}\left(G_{i}-\{x\}\right) \cup H_{p}, & \text { jika } x \in G_{i} \\ \left(\left(G_{i}-\{x\}\right) \cap\left(G_{j}-\{x\}\right)\right) \cup\left(H_{p} \cup H_{q}\right), & \text { jika } x \in G_{i} \cap G_{j} \\ G_{i}, & \text { jika } x \notin G_{i}\end{array}\right\}\right.$

Dimana $C_{3}=C_{1} \circledast_{x} C_{2}$ adalah koteri- $k$ tak-terdominasi atas semesta tak-kosong $U_{3}$. Saran untuk penelitian berikutnya yaitu bagaimana mencari sifat-sifat definisi operasi join diperluas terhadap penggabungkan dua bentuk koteri- $k$ mayoritas baik untuk koteri- $k$ mayoritas terdominasi maupun untuk koteri- $k$ mayoritas tak-terdominasi.

\section{UCAPAN TERIMA KASIH}

Sebagai rasa syukur dalam menuntaskan penelitian ini, maka tak lupa mengucapkan rasa terima kasih kepada pembimbing yang telah memberikan bantuan, masukan, dan saran serta keluarga dan teman-teman yang selalu memberikan motivasi dalam menuntaskan penulisan jurnal ini.

\section{DAFTAR PUSTAKA}

Agrawal D. \& El-Abbadi A. (1991). An efficient and fault-tolerant solution for distributed mutual exclusion. ACM Trans. Comput. Systems 9 (1): 222-232.

Garcia H. \& Barbara D. (1985). How to assign votes in a distributed system. J .ACM 32(4): $841-860$.

Ishak N., Lawi A., \& Amir K. A. (2016). Operasi Penggabungan Koteri Tak-terdominasi Dengan Unsur Tereliminasi. Makassar: Hasanuddin University.

Jiang J. \& Huang S. (1994). Obtaining Nondominated $k$-Coteries for Fault-Tolerant Distributed k-Mutual Exclusion. IEEE Transactions on Computer: 30043 R. 0.C.

Kakugawa H., Fujita S., Yamashita M., \& Ae, Tadashi. (1994). A distributed k-mutual exclusion algorithm using k-coterie. Information Processing Letters, 49: 213-218.

Lamport L. (1986). The Mutual Exclusion Problem Part I: A Theory of Interprocess Communication. National Science Foundation under grant number, MCS 7816783.

Lawi A., Oda K., \& Yoshida T. (2005). A Quorum Based Group k-Mutual Exclusion Algorithm for Oper Distributed Environments. Parallel and Distributed Processing and Applications: 119-125.

Lawi A., Oda K., \& Yoshida T. (2006). A Quorum based distributed conflictresolution algorithm for bounded capacity resources. Lecture Notes in Computer Science (LNCS), Springer Verlag-Berli, 4331: 135-144.

Maekawa M. (1985). A $\sqrt{n}$ algorithm for mutual exclusion in decentralized systems. ACM Trans. Comput. Systems 3(2): 145-159. 
Manabe Y. \& Tajima N. (2004). (h, k)-Arbiters for h-out-of-k Mutual Exclusion Problem. Theoretical Computer Science 310: 379-392.

Najafi S. (2008). A New GA - Based and Graph Theory Supported Distribution System Planning. IEEE Transactions on Parallel and Distributed System, 2(8).

Neilsen M. L. \& Mizuno M. (1992). Coterie Join Algorithm. IEEE Transactions on Parallel and Distributed System, 3(5): 759-765.

Neilsen M. L. \& Mizuno M. (1994). Nondominated k-Coteries for Multiple Mutual Exclusion. Information Processing Letters, 50: 247-252.

Neilsen M. L. (1997). Properties of Nondominated k-Coteries. J. Systems Software by Elsevier Science Inc: 37 91-96. 